\title{
Trabalhadores Temporários para o Café: Mecanização e Núcleos Coloniais em São Paulo, 1895-1911 *
}

\author{
Cláudia Alessandra Tessari \\ Professora (UNIFESP/SP) \\ Endereço: Rua Angélica, 100 - Osasco - São Paulo - SP - Brasil \\ CEP: 06110-295 -E-mail: ctessari@unifesp.br
}

Recebido em 29 de agosto de 2012. Aceito em 08 de novembro de 2013.

\section{Resumo}

Este artigo examina o problema da mão de obra diante da expansão cafeeira ocorrida em São Paulo e da queda dos preços do café, na virada do século XIX para o século $X X$. Mais especificamente, este texto trata de alguns aspectos do debate que destacava a necessidade de redução dos custos com mão de obra frente às dificuldades que envolviam a contínua expansão da produção cafeeira naquele momento. As propostas discutidas no artigo privilegiavam a mecanização do cultivo e a flexibilização do trabalho por meio da contratação de trabalhadores temporários. A implantação de núcleos coIoniais estrategicamente localizados poderia contribuir para incrementar a oferta desse tipo de trabalhador. A análise deste debate mostra que segmentos da elite econômica paulista tinham clara consciência, já naquele momento, de que somente a garantia de oferta abundante de mão de obra para os momentos de demanda intensa de trabalho na agricultura permitiria a mecanização e a flexibilidade de contratação.

\section{Palavras-Chave}

trabalho temporário, núcleos coloniais, mecanização, café, São Paulo

\begin{abstract}
This article analyses the concerns related to the seasonal labor as a result of the coffee farming growth along with the price decline of coffee, at the transition from XIX century to XX century. Particularly, this article debates the need of cost reduction in labor due to the challenges involved in the continuous expansion of the coffee farming at that moment. The proposal discussed in the article favored the mechanization of part of the work in the coffee agriculture in association with the contractual hiring of seasonal workers. The creation of colonial nucleus, in strategic locations, could contribute to increment this type of workforce. The analysis of this discussion demonstrates that segments of the Sao Paulo economic elite were aware that having ample availability of labor force was the only way to allow mechanization, flexibility and cost reduction at the times of intense agricultural work.
\end{abstract}

\section{Keywords}

seasonable work, colonial nucleus, mechanized, coffee, Sao Paulo

\section{JEL Classification}

N36, N56, N96

\footnotetext{
- Agradeço aos comentários e sugestões do revisor ad hoc, os quais possibilitaram importantes melhorias na versão acabada deste texto. Agradeço à Fundação de Amparo à Pesquisa do Estado de São Paulo (FAPESP) pelo apoio financeiro à parte da pesquisa.
} 


\section{Introdução}

Com a colonização das terras marginais das estradas de ferro em tráfego [...] teríamos dentro de alguns anos conseguido ao mesmo tempo multiplicar as fontes de riqueza publica pela variedade das produções - crear um número considerável de viveiros de trabalhadores rurais, aptos para prestarem seus serviços na época das fainas agricolas da lavoura cafeeira, e ipso facto, tornar intensivas as nossas culturas. Em vez da instabilidade de hoje, não obstante os pesados sacrificios que custa ao fazendeiro a manutenção do excessivo pessoal permanente, teríamos então o trabalho regularizado, sem mais onus que o do pagamento pelos serviços feitos. (SECRETARIA dos Negócios da Agricultura, 1905, p. 294, grifo do autor)

Os anos estudados neste artigo $^{1}$ são marcados pela crise na lavoura cafeeira. A partir de 1895, o preço do café sofreu significativa queda, alcançando entre 1901 e 1910 menos da metade dos preços em réis praticados em 1893. Paralelamente, há a valorização do mil réis, o que tornou mais barata a viagem para o exterior e estimulou a saída de imigrantes estrangeiros, resultando em saldos migratórios negativos a partir de 1901. Os baixos preços do café associados aos altos gastos para a manutenção da imigração em massa subsidiada para São Paulo puseram em evidência a necessidade de redução dos custos da produção cafeeira. Esta, por sua vez, estava relacionada, segundo parte da elite econômica e política paulista, à necessidade de modificação da política de mão de obra e do sistema de trabalho que vinham sendo seguidos - o subsídio do transporte de trabalhadores imigrantes associado ao regime de colonato nos cafezais. (Sallum Jr., 1982, p. 110; Holloway, 1984, p. 265)

As críticas ao sistema de imigração subsidiada e ao regime de colonato seguiam vários sentidos: o gasto excessivo do Estado para trazer trabalhadores que, no final das contas, permaneciam por pouco tempo nas fazendas, tornando constante a necessidade de imigração

1 Agradeço aos comentários e sugestões certeiros do revisor ad hoc, os quais possibilitaram importantes melhorias na versão final deste texto. 
subvencionada; o tipo de imigração que trazia o trabalhador para a lavoura sem dar atenção à necessidade de fixá-lo no país; e a rigidez do colonato que, ao manter o trabalhador no interior da fazenda durante todo o ano, limitava a capacidade de diminuição dos custos por meio do cultivo mecânico associado à dispensa de trabalhadores na entressafra.

Este artigo analisa alguns aspectos deste debate, especialmente no que se refere às propostas que privilegiavam a mecanização do cultivo e a flexibilização do trabalho por meio da contratação de trabalhadores temporários. Os núcleos coloniais estrategicamente localizados poderiam contribuir para incrementar a oferta deste tipo de trabalhador.

O exame deste debate mostra que naquele momento já existia a clara consciência de que a produtividade e a lucratividade da lavoura dependiam da possibilidade de mecanização e da flexibilização do trabalho, porém, estas esbarravam em alguns fatores, o mais importante, a falta de mão de obra abundante que garantisse a oferta elástica de trabalhadores nos momentos de maior necessidade de trabalho.

Este debate foi travado principalmente nas páginas da Revista Agricola, periódico pago, de circulação nacional, veículo de divulgação da Sociedade Paulista de Agricultura, a qual agregava importantes fazendeiros e políticos paulistas em torno da questão da modernização da agricultura, entendida naquele período como a implantação de princípios científicos no campo (mecanização, adubação, aclimatação de espécies, etc.). Muitos dos agentes técnicos que tratavam deste debate e escreviam na Revista Agrícola assinavam também artigos publicados no Boletim de Agricultura, periódico trimestral gratuito, editado pelo Instituto Agronômico de Campinas, órgão da Secretaria de Agricultura, Commercio e Obras Publicas. ${ }^{2}$

Além destes dois periódicos, outras fontes utilizadas neste texto foram os Relatórios da Secretaria da Agricultura, Commercio e Obras Publicas e Almanaques Agrícolas.

O artigo está dividido em duas seções além desta Introdução e das Considerações Finais. A primeira, trata das discussões acerca da

2 Para mais detalhes sobre a relação entre a Revista Agricola e a Sociedade Paulista de Agricultura e sobre a relação da Revista e com o Estado, ver Ferraro (2012). 
mecanização de parte do processo de produção do café, o trato ou cultivo, o que permitiria a dispensa de trabalhadores na entressafra porém traria outro problema: a necessidade de poder contar com abundância de trabalhadores disponíveis para serem arregimentados na época da colheita. A segunda trata do debate acerca dos núcleos coloniais estrategicamente localizados os quais seriam os viveiros de trabalhadores onde os fazendeiros buscariam a mão de obra temporária sazonal para as épocas de pico de trabalho nas fazendas.

\section{O Debate em torno da Mecanização}

O padrão de trabalho na lavoura cafeeira era marcado por descontinuidades no que se referia ao tipo de tarefa, à intensidade de trabalho e à quantidade de mão de obra necessária para as diversas fases da produção. De modo geral, o trabalho nas lavouras de café já constituídas pode ser dividido nas seguintes etapas: trato ou cultivo (o ato de capinar o café e mantê-lo livre de mato e ervas daninhas); e, colheita (ato de colher o fruto maduro). Estas duas etapas apresentam diferenças significativas entre as quantidades e os ritmos de trabalho necessários para realizá-las. O trato (ou cultivo) durava cerca de oito meses e requeria pouco trabalho, pois o trabalhador, neste período, devia apenas capinar o cafezal entre quatro e cinco vezes, representando, portanto, pequena demanda por mão de obra. A colheita, a qual durava cerca de quatro meses, exigia trabalho intenso tanto em horas trabalhadas quanto em ritmo de trabalho e em número de trabalhadores. Por volta do ano de 1900, estimava-se que o período da colheita requeria cerca de $54 \%$ mais mão de obra quando comparado com o período da entressafra (período do trato) (Estatística especial da lavoura do café, 1900, p. 6).

O trabalho na cafeicultura era marcado, portanto, pela sazonalidade e pela instabilidade na demanda por mão de obra, visto que o processo produtivo requeria diferentes tarefas e ritmos ao longo do ciclo de produção, existindo momentos de muito trabalho (geralmente na época da colheita) seguidos de momentos em que pouco se trabalhava. Vindo agravar este problema da sazonalidade, estava a imprevisibilidade da colheita, pois esta variava muito de ano para ano: "É certo, porém, que mesmo na melhor época essa produtividade [do cafezal] não é idêntica todos os anos, mas intensifica-se, ao contrário, de dois em dois anos, 
sendo considerável a diferença entre uma boa safra e uma safra recorde" (Davatz, 1980, p. 64). ${ }^{3}$ Sendo assim, percebe-se que a demanda por mão de obra variava não só ao longo do ano, mas de um ano para outro. (Tessari, 2010, p. 57- 65)

Uma atividade que tem padrão de demanda por trabalho deste tipo - sazonal, descontínuo e incerto - requer, para melhor gestão de seus custos, recursos flexíveis, em especial o recurso de produção trabalho.

A escravidão havia contornado em parte este problema por meio da autossuficiência das fazendas. Na entressafra, ou nos anos de más colheitas, quando a necessidade de trabalho na lavoura comercial era menor, os escravos se dedicavam às lavouras de alimentos, ao cuidado com os animais, às benfeitorias na fazenda, etc. (Gorender, 1985, p. 210). $\mathrm{Na}$ transição da escravidão para o trabalho livre, o sistema de colonato contornava este problema de maneira parecida: cedia terras para que os colonos mantivessem suas roças de alimentos e alguma criação nas épocas mortas do café (épocas em que o café requeria pouco ou nenhum trabalho) e oferecia remuneração extra para aqueles que se dedicassem às benfeitorias. (Sallum Jr, 1982; Rezende, 2006). Desta maneira, tanto as fazendas escravistas quanto as do colonato mantinham um regime de trabalho que contornava, em parte, os problemas oriundos da sazonalidade: permitia aos trabalhadores formas de ocupação produtiva de seu tempo no período da entressafra; liberava as fazendas de arcar com os custos de manutenção do trabalhador nos momentos em que seu trabalho não era requerido na grande lavoura; e, ao mesmo tempo, mantinha uma reserva de mão de obra interna às fazendas que eram utilizadas na época de pico de trabalho (Sallum Jr., 1982, p. 238; Stolcke e Hall, 1983, p.110; Rezende, 2006, p. 6; Tessari, 2010, p. 157-162).

No entanto, se o colonato era um sistema que permitia certa flexibilidade e o rebaixamento dos custos monetários, possibilitando à fazenda driblar em parte os problemas derivados da sazonalidade da agricultura, ao mesmo tempo era um impeditivo à maior flexibilização do trabalho e maior rebaixamento dos custos com mão de obra, pois, segundo fazendeiros e técnicos que escreviam nos periódicos analisados, era um empecilho à mecanização do trato.

3 Bassanezi, baseando-se na série de dados sobre colheita e produção na fazenda Santa Gertrudes, percebeu a tendência de, em duas colheitas consecutivas, haver uma diferença de produção de 30\%. Bassanezi, 1973, p. 90. 
Mecanizar, naquele período, significava utilizar capinadores mecânicos (uma espécie de charrua puxada por cavalos e guiada por um homem) na etapa do trato ou cultivo e dispensar parcela importante da mão de obra necessária nesta etapa.

Os capinadores existentes na época permitiam significativa redução da necessidade de mão de obra constante, ou seja, aquela necessária para manter o cafezal limpo ao longo dos 8 meses entre uma colheita e outra. Já em 1895, a estimativa era que com os capinadores existentes poderia se economizar mais de $90 \%$ de trabalho: "um homem e um a dois animais fariam o serviço de doze a quatorze trabalhadores". (Queiroz, 1895, p. 93)

O sistema de colonato era considerado um empecilho para a mecanização porque o uso dos capinadores exigiria a inutilização das terras entre as fileiras de café (em que os colonos costumavam plantar suas culturas alimentares) e, o que é essencial para nossa discussão, aumentaria a discrepância entre o quantum de trabalho necessário para a etapa do trato ou cultivo e o quantum de trabalho para a etapa da colheita, aumentando, portanto, o problema oriundo da sazonalidade da agricultura.

Caso a fazenda optasse por mecanizar o trato e manter o trabalhador residindo em suas terras, mais áreas seriam necessárias para aproveitar o maior tempo ocioso do trabalhador. Estas terras, no entanto, não poderiam estar intercaladas aos pés de café, visto que as culturas alimentares nas ruas do cafezal era outro limitador da mecanização: "Para fazermos uso das machinas nos cafézaes é necessario porém que nelles não se plantem cereaes, os quaes deverão ser cultivados a parte em terrenos apropriados. O colono está habituado a isso, de modo que temos de deshabitua-lo e compensa-lo ainda." (Souza, 1905, p. 210)

Além dos motivos expostos acima, que requeriam a mudança no sistema de trabalho nas fazendas, a possibilidade da mecanização do trato também esbarrava em uma série de motivos de ordem técnica, tais como a declividade do terreno, a natureza do solo e a distância entre as plantas e, principalmente, na "falta de abundancia de braços fixos ou nomades por ocasião da colheita" (Duarte, 1913, p. 303). Este último fator estava relacionado ao fato de o trabalho da colheita, fase do processo de produção que representava o pico de necessidade de trabalho, ter de ser feito à mão: 
Há, na cultura do café, uma phase em que não se pode empregar as machinas: é a da colheita. A colheita de café reclama durante quatro meses, mais ou menos, um afanoso trabalho. Nos paizes muito povoados, torna-se muito facil esse serviço, porque se consegue de prompto o pessoal preciso; mas no Brasil isso não acontece; pelo que os fazendeiros são obrigados a manter um grande numero de trabalhadores durante todo o anno, unicamente por causa da colheita. Tem-se pois, aqui, uma grande dificuldade contra o abaixamento do preço do café. (Fauchère, 1914, p. 402)

A mecanização, portanto, se colocada em prática, reduziria o número de trabalhadores necessários para o trato ou cultivo, mas, por outro lado, aumentaria a discrepância entre o quantum de trabalho necessário para o trato e o quantum de trabalho necessário para a colheita. A mecanização possível na época, então, ao se referir apenas a uma fase do processo de produção, poupava trabalho, mas o fazia na fase de menor necessidade de mão de obra, mantendo inalterada a necessidade de trabalho na fase de maior demanda (a colheita). Desta maneira, a mecanização acabava por aumentar a dependência do capital por trabalho sazonal extra fazenda e, portanto, somente seria viável se pudesse contar com a "abundância de braço fixo ou nômade por occasião das colheitas".

Para Carlos Duarte, que escrevia sobre a possibilidade da mecanização do café em 1913, apesar de todos os fatores expostos impossibilitarem o uso dos capinadores, era este último o principal problema que ainda impedia a utilização dos capinadores:

Se indagarmos porque assim procedem [mantendo o uso da enxada ao invés dos capinadores mecânicos] iremos com certeza achar o motivo [...] principalmente nas dificuldades com que arcam por occasião da colheita. Effectivamente, a cultura mecanica, exigindo pessoal pouco numeroso, mais ou menos a vigesima parte do que exigiria a cultura manual, traz o grave inconveniente da deficiencia de braços justamente na epocha em que mais fazem sentir a sua falta. (Duarte, 1913, p. 304) 
Naquele momento em que o mercado de trabalho ainda estava em gestação, aumentar a discrepância entre as exigências de trabalho nos momentos de baixa e a exigências dos momentos de pico significava tornar vulnerável o negócio da grande lavoura, pois a deixaria extremamente dependente do trabalhador extra fazenda em um momento no qual o exército de reserva ainda estava em formação.

Sobre este último aspecto, o Boletim da Agricultura, na sessão Condições da Lavoura, que tratava das condições mensais da agricultura em São Paulo, trazia:

Quando a nossa lavoura não precisar ter nas fazendas mais do que o pessoal de custeio ordinário e poder recorrer na época da colheita a um pessoal externo às fazendas [...] o lavrador ver-se-á mais desembaraçado de despesas e poderá encurtar a duração da epocha da colheita, o que será de superior vantagem [...]. (CONDIÇÕES da lavoura, 1901, p. 509)

Isso só seria feito, como realmente o foi, cinquenta anos depois, quando estivesse garantida a elasticidade da oferta de mão de obra, em outras palavras, quando a rápida adequação do quantum de mão de obra às demandas cíclicas e sazonais da agricultura estivesse garantida pela abundância de braços expropriados (Silva, 1981; Mello, 1976).

Além do mais, é importante ter em mente que a agricultura tinha (e, em boa medida, tem até hoje) um processo de trabalho que é desfavorável ao capital: a diferença entre o tempo de trabalho (quantidade de tempo que o trabalhador dedica às tarefas do processo produtivo - preparar a terra, plantar, cultivar e colher) e o tempo de produção (quantidade de tempo necessária para que o produto esteja pronto). Para o café, por exemplo, estimava-se na época um tempo de trabalho de apenas 175 dias comparado com um tempo de produção de 360 dias. (GAZETA DE PIRACICABA, 14 ago. 1888, p. 3). Logo, quase metade dos dias do ano o trabalhador ficaria sem ocupação na lavoura cafeeira e, nesse tempo, deveria dar conta dos meios de subsistir. 
$\mathrm{Na}$ agricultura, portanto, a menos que a mecanização incidisse tanto sobre a fase inicial (no caso do café, a fase do trato) quanto sobre a fase final (a colheita), ela não alteraria o tempo de produção, podendo produzir simplesmente um aumento do tempo de não trabalho (Silva, 1981, p. 33).

Naquele momento, quando não havia exército de reserva plenamente formado, mecanizar o trato significaria apenas aumentar os tempos mortos do trabalho no cafezal sem, contudo, garantir a flexibilização dos custos com trabalho, tendo em vista que não havia a garantia de poder contar com abundância de trabalhadores quando a lavoura cafeeira os requisitasse. Contrariamente, poderia apenas implicar mais altos custos de contratação, visto que todas as fazendas estariam demandando maior quantidade de mão de obra ao mesmo tempo.

Seria necessário, portanto, que as fazendas tivessem garantido o suprimento de mão de obra extra fazenda para as fases de pico de trabalho, permitindo-lhes diminuir a dependência em relação aos trabalhadores permanentes (colonos) e mecanizar o trato. Assim, seria a abundância de trabalhadores sazonais para as fases do trabalho que requeriam mão de obra temporária em grande quantidade, o que permitiria a mecanização e a flexibilização do trabalho.

Si se podesse obter gente bastante [...] assim também lucraria o fazendeiro, que hoje precisa manter durante todo o anno o pessoal necessário para a colheita. Elle poderia reduzir o seu pessoal á metade e poderia cultivar os seus cafezaes com machinas agricolas, o que ate hoje poucos fazem exactamente pelo motivo de serem obrigados a conservar um grande pessoal durante o intervallo das colheitas." (Kulmann, 1901, p. 32, grifo do autor)

A formação do exército de reserva permitiria o rebaixamento dos custos com mão de obra, fosse diretamente, pelo rebaixamento dos salários, fosse indiretamente, por permitir a flexibilização do trabalho e o aumento da produtividade proveniente da mecanização do trato. 
Por volta de 1899, Carlos José de Arruda Botelho, médico, político e proprietário de diversas fazendas no interior do Estado, testou o emprego de capinadores mecânicos, os capinadores da marca Planet. "Os seus cafezaes, que exigiam a permanência de trinta famílias para um cultivo conveniente tiveram trato muito mais cuidado apenas com dez famílias e camaradas de costume, com pouco diferença". (Carmo, 1899, p. 176)

No entanto, ao diminuir o número de famílias com as quais costumava manter limpo seu cafezal (de trinta para dez), Carlos Botelho viuse embaraçado com a falta de trabalhadores na ocasião da colheita: "sentiu-se profundo desequilibrio por occasião da coroação e colheita porquanto essa se atrasou”. (Carmo, 1899, p.176)

Foi Antonio Gomes Carmo, agrônomo e proprietário da Revista Agrícola a partir de 1897, quem relatou esta experiência na fazenda de Carlos Botelho, concluindo que "o emprego do capinador mechanico para o cultivo do café exige[ia] como corollario uma organisação de trabalho mais racional, sem o que pouco vale, porque afinal fica sempre de pé a questão da colheita, que só se faz a braço". (Carmo, 1899, p. 176)

Para ele, a solução estaria em fixar o trabalhador ao solo ao lado das fazendas, nas terras baixas mais sujeitas a geadas e, portanto, não cultivadas com café. Assim as fazendas teriam trabalhador "fixado ao solo e prompto a acudir aos chamados do fazendeiro no momento da colheita, que se effectua justamente, quando o colono tem concluido a colheita de cereaes e se acha disponivel e desejoso de occupação que remunere o seu trabalho sob a forma de salarios". (Carmo, 1899, p. 176)

Para Gomes Carmo, o problema estava no sistema de colonato que, mantendo pessoal excessivo para garantir a colheita, limitava o uso de tecnologia poupadora de mão de obra. A solução para a maior flexibilização do trabalho estava em ter trabalhadores ao lado das fazendas a quem poderiam recorrer nos momentos de pico de trabalho: "corrija-se a organização do trabalho colonial, fixe-se o colono junto às fazendas e o capinador mechanico prestará optimo serviço no cultivo do café." (Carmo, 1899, p. 179) 
Neste momento, abriu-se novamente o debate em torno dos núcleos coloniais para atender às necessidades da grande lavoura, debate este intrinsecamente vinculado às discussões sobre a necessidade de mecanização e de remodelação do sistema de trabalho, ambos vistos como elementos essenciais para o rebaixamento dos custos da lavoura cafeeira.

\section{Núcleos Coloniais: Viveiros de Braços para a Colheita}

Em São Paulo, desde 1886, o governo do estado tinha praticamente abandonado a política de colonização, voltando-se para subsidiar e atrair imigrantes para o engajamento na grande lavoura, enquanto a existência dos núcleos coloniais estava restrita a desenvolver centros de agricultores voltados para a produção de gêneros alimentícios e também para atuar como fator de propaganda do progresso deste Estado no exterior. Durante o regime republicano em São Paulo, podem-se distinguir duas fases distintas que nortearam a criação dos núcleos. Uma primeira fase, que se estende até aproximadamente 1896/97, e uma segunda, iniciada em 1900, a qual, segundo Regina Gadelha, define mais claramente o papel destes núcleos no processo de acumulação e expansão cafeeira e que esteve associada à estratégia de viveiros de braços para a colheita (Gadelha, 1982, p. 150).

A primeira fase da política de núcleos coloniais da Primeira República em São Paulo foi mais apoiada pelos representantes dos interesses do Norte do estado, que viram na política de núcleos a possibilidade de valorização de suas terras e da restauração da combalida economia regional. Portanto, nesta primeira fase, a zona mais favorecida pela criação de núcleos foi o Norte do Estado, com quatro núcleos, seguida da região circunvizinha da capital, com três núcleos (Gadelha, 1982, p. 158).

Os núcleos localizados na região Norte foram instalados em propriedades adquiridas pelo Estado constituídas por terras esgotadas para plantio em grande escala do café ou impróprias para sua cultura. Provavelmente seus proprietários não obteriam comprador, numa época de escassez de moedas, capital e crédito, não fosse a ação assumida pelo Estado. Já os núcleos localizados na região circunvizinha da capital vinham suprir outra necessidade: produzir alimentos para 
a região em um momento em que terras apropriadas e braços estavam sendo canalizados para a produção cafeeira (Gadelha, 1982, p. 164). Na segunda fase, a que nos interessa neste momento, os novos núcleos estavam dentro das zonas cafeeiras e em regiões cortadas pelas estradas de ferro, servindo aos interesses da grande lavoura como viveiros de trabalhadores.

Para os defensores da criação dos núcleos nesta segunda fase, a sua localização deveria ocorrer de forma a atender critérios mais técnicos e econômicos do que políticos, permitindo-lhes um melhor rendimento produtivo, sem descuidar dos interesses dos grandes fazendeiros de café, quer pela valorização das áreas marginais às suas fazendas, quer fornecendo trabalhadores em épocas de maior demanda de trabalho. Pelo fato de estarem localizados nas zonas cafeeiras, teriam maior possibilidade de sucesso que os núcleos anteriormente fundados no estado, visto que os anteriores estavam localizados em terras impróprias ou em localidades sem vias de comunicação e longe dos mercados (Kulmann, 1901, p. 33).

Além do mais, para seus defensores, os núcleos teriam maior possibilidade de sucesso porque seus moradores teriam a possibilidade de complementação da renda com o trabalho na colheita das fazendas. Assim defendia Carlo Botelho no seu relatório anual de gestão à frente da Secretaria da Agricultura do Estado:

Devemos tratar de colonisar, em primeiro logar, as terras servidas por estradas de ferro e situadas dentro das zonas em que se encontram as fazendas de café e onde são abundantes as terras proprias para outras culturas [...] A colonisação ahi terá assegurado o seu bom êxito, não só porque os productos dos núcleos terão facilidade de transporte para os mercados, como tambem porque os colonos terão, na época em que lhes sobra tempo, trabalho seguro e remunerador na colheita e outros serviços da grande lavoura. (SECRETARIA dos Negócios da Agricultura, 1905, p. 132.) 
Do ponto de vista da ampliação da oferta de mão de obra sazonal, pensava-se que os núcleos poderiam vir a se constituir em viveiros de trabalhadores, onde as fazendas poderiam arregimentar a mão de obra necessária para as diferentes épocas de trabalho sem ter de manter em seu interior áreas para a manutenção destas famílias, como vinha ocorrendo no colonato, afinal "Nas regiões em que abundam as pequenas propriedades e nas quaes a cultura cerealifera é largamente praticada, há quase sempre abundancia de braços [...]." (Duarte, 1913, p. 304)

Assim, os núcleos coloniais, ao "criar a pequena propriedade ao lado da grande, seriam os viveiros de trabalhadores" (Gavião Peixoto, 1905 , p. 34) onde as fazendas buscariam mão de obra temporária, permitindo contornar parte dos problemas do colonato frente às exigências sazonais do trabalho agrícola, tal como o de ter de manter no período da entressafra "excessivo pessoal permanente" (SECRETARIA dos Negócios da Agricultura, 1905, p. 294) como garantia para os dos momentos de pico de trabalho:

As colônias espalhadas pelo Estado offerecerão em certa quadra do anno trabalhadores úteis e desoccupados que procurarão novos lucros na colheita que lhes proporcionará a lavoura cafeeira, dando logar a que esta poupe não só o empate na construção de numerosas casas, até aqui destinadas a manter os braços precisos para a garantia da safra, como os gastos avultados do custeio pela substituição das famílias de trabalhadores pelos instrumentos aperfeiçoados de cultura (Malta, 1905, p. 2, grifo do autor)

Ainda segundo seus defensores, os núcleos deveriam se dedicar a culturas cujas exigências de trabalho fossem intercalares às exigências na grande propriedade, não concorrendo com o café quanto à demanda por mão de obra. A lavoura de cereais (como era chamada a cultura de alimentos, tais como arroz, feijão, milho e batata) ou do algodão herbáceo (espécie plantada em São Paulo no período) eram as alternativas mais plausíveis. 
Além de que, formariam viveiros de trabalhadores que auxiliariam a lavoura nas colheitas de café, para a qual sempre luctam os lavradores por falta de braços, que facilmente conseguirão nos nucleos, sendo as colheitas, como são, nos meses de desoccupação para elles e para suas famílias, podendo todos, com vantagens recíprocas, empregar-se naquela laboração. (Gavião Peixoto, 1905, p. 34, grifo do autor)

Conforme dados do Calendário Agrícola Paulista publicado anualmente nos Almanaques Agrícolas, a produção dos cereais e do algodão herbáceo ocorria em São Paulo entre agosto (época do plantio) e abril (fim da época de colheita), não exigindo mão de obra, portanto, nos meses entre maio e julho, período de pico de trabalho no café.

Os ciclos de produção dos cereais, no entanto, apesar de serem intercalares ao ciclo de produção do café, possuíam algumas tarefas que coincidiam no tempo com as do cafezal, como era o caso da preparação das sementeiras para a plantação as quais deviam ser feitas em julho, justamente época de colheita do café, e, portanto, momento de pico de trabalho nas grandes fazendas (Sobrinho, 1906, p. 20-50).

Este era mais um motivo para que os núcleos estivessem localizados próximos às fazendas, pois a proximidade permitiria que o trabalhador efetuasse o trabalho no seu lote e colhesse café nas grandes propriedades. Ainda, deveria estar próximo às ferrovias a fim de permitir o escoamento da produção dos lotes, também para garantir que pudessem funcionar como viveiros de braços temporários, uma vez que a proximidade dos trilhos facilitaria o transporte dos trabalhadores para as fazendas de café mais distantes.

O subsídio do transporte de trabalhadores dos núcleos coloniais para se engajarem nas colheitas de café das fazendas foi previsto, inclusive, no Decreto ${ }^{0} 1.355$ que criou a Agência Oficial de Colonização e Trabalho, em 1906, durante a gestão de Carlos Botelho na Secretaria da Agricultura, Commercio e Obras Publicas: 
Art. 43. - Durante o período das colheitas, a Agencia Official de Colonização e Trabalho deverá providenciar de accordo com as instrucções do Secretario de Agricultura, no sentido de ser facilitado aos colonos localizados nos nucleos coloniaes o seu transporte de ida e volta em estrada de ferro, quando se ajustarem para trabalhar nas fazendas. (SÃO PAULO. DECRETO n. 1.355 de 10 de abril de 1906).

Desta forma, contemplando também os interesses da grande lavoura, a política de núcleos coloniais passou a ter seu papel reinterpretado, sendo positivamente reavaliada por alguns fazendeiros e técnicos como reservatórios humanos para os períodos agrícolas de maior atividade (Petrone, 1985, p. 93-133; Gadelha, 1982, p. 150; Beiguelman, 1971, p. 91). Somente desta maneira - fornecendo braços para a grande lavoura e não concorrendo com ela neste quesito - a política de núcleos coloniais poderia ser aceita pelos fazendeiros, pois a verba para a compra das terras, loteamento e construção da infraestrutura seria proveniente da renda do café, principal fonte de renda do Estado de São Paulo:

A vida em São Paulo é tão relacionada com a cultura do café que a nova política de colonização não teria tido chance de se tornar popular se os próprios fazendeiros não tivessem apoiado a ideia. Eles são mais alarmados que qualquer outro pela instabilidade do trabalho agrícola, porque a falta de braços no momento da colheita pode ser desastrosa [assim] ponderaram que estabelecendo colonos proprietários a uma pequena distância das plantações de café, eles teriam à mão um corpo de trabalhadores que necessariamente lhes seriam um público fiel a quem eles poderiam recorrer no momento necessário. [...] Este argumento selou a aliança entre defensores da grande e da pequena propriedade. (Denis, 1911, p. 226) 
Em 1908, Antonio Candido Rodrigues, sucessor de Carlos Botelho na Secretaria da Agricultura e também defensor da política de núcleos coloniais como viveiro de braços, abria o Relatório da Secretaria, assegurando que a intenção da nova política sobre os núcleos não era concorrer com a grande lavoura em questão de braços:

No Estado de S. Paulo, onde predomina a grande lavoura e onde o Estado tira as suas rendas principalmente do seu quasi unico producto, o café, só se pode planejar e realisar uma colonisação razoavel e practica de maneira que aquella não venha a soffrer com esta, ou por outra, que continuem á sua disposição, como antes, os braços precisos. Porque da renda, que o café produz, é que tem de sahir as despesas a fazer com a colonisação. (SECRETARIA dos Negócios da Agricultura, 1908, p. 76)

Pode, assim, na primeira década do século XX, ser reanimada a política de núcleos coloniais fundados pelo Estado como um suplemento para as necessidades da lavoura de café, e não como um programa que competiria com ela. Enquanto no sul do Brasil estas colônias eram vistas como um modo de tomar posse de terras fronteiriças desocupadas, em São Paulo elas deviam ser estabelecidas dentro das zonas cafeeiras, para se tornarem fontes de produtos alimentícios localmente produzidos e de mão de obra extra durante o período da colheita.

Em seis anos, entre 1905 e 1911 nas gestões de Carlos Botelho (1904-1907) e Antonio Candido Rodrigues (1908-1911) foram criados onze núcleos coloniais estatais. Os núcleos fundados entre 1905 e 1907, com sua respectiva localização, foram: núcleo Jorge Tibiriçá (localizado no atual município de Corumbataí); Nova Odessa (no atual município de Nova Odessa); Conde do Pinhal (em Ubatuba); Gavião Peixoto (no atual município de Gavião Peixoto) e Nova Europa (no atual município de Nova Europa).

Entre 1910 e 1911, foram fundados: Nova Veneza (no atual município de Sumaré); Boa vista (em Jacareí); Conde do Parnahyba (em Conchal); em Juquiá (em Juquiá); Visconde de Indaiatuba (em MogiMirim); e Martinho Prado (também em Mogi-Mirim). 
A maior parte destes núcleos estava encravada em terras de grandes fazendas, como é o caso da Sesmaria do Cambuhy, de propriedade do Conselheiro Bernardo Avelino Gavião Peixoto, que compreendia cerca de oito fazendas de café, abrangendo terras situadas nos municípios de Araraquara, Matão e Ibitinga. Os três núcleos ali formados (Gavião Peixoto, Nova Paulicéia e Nova Europa) estavam encravados em meio a estas fazendas e situados em pleno coração da zona produtora de café (Gadelha, 1982, p. 240).

Também é o caso da Sesmaria de Conchal cujas terras deram origem aos núcleos de Martinho Prado Júnior, Visconde de Indaiatuba e Conde de Parnahyba. Fundados em terras de antigas fazendas de café e cortados pela Estrada de Ferro Funilense, representavam o avanço da pequena propriedade em direção a zonas ainda pouco povoadas. Segundo Gadelha, que estudou a política de núcleos coloniais deste período, esperava-se que estes viessem a diminuir o poder de barganha dos trabalhadores das fazendas locais, que frequentemente ameaçavam greves buscando melhores salários (Gadelha, 1982, p. 200).

Além de tentar contemplar os interesses da grande lavoura quanto à flexibilidade dos custos com mão de obra, é importante lembrar que, nesta segunda fase, a política de núcleos coloniais estava vinculada à possibilidade de assistir fazendeiros falidos. O Estado, adquirindo as propriedades por meio da compra ou arcando com os custos do loteamento de terras doadas por grandes proprietários (como foi o caso dos núcleos formados nas antigas áreas de propriedade do Conselheiro Gavião Peixoto), acabava por beneficiar diretamente os fazendeiros de café que lucravam tanto com a venda dos lotes quanto com a possibilidade de contar com trabalhadores sazonais para as épocas de pico de trabalho: "No entanto, é fácil de ver que a colonização das terras particulares traz a dupla vantagem de facilitar a venda das mesmas, por melhores preços, e de fornecer, nas épocas apropriadas, um bom contingente de braços aos próprios fazendeiros que deles careçam." (SECRETARIA dos Negócios da Agricultura, 1909, p. 302)

Mesmo contemplando os interesses da grande lavoura e apesar do ônus que a política de imigração em massa subvencionada significava para as finanças do Estado, a maior parte dos fazendeiros nunca se convenceu das vantagens comparativas dos núcleos. 
Assim, apesar da criação de alguns deles por parte do governo e da iniciativa particular, nunca foram assumidos em escala significativa os projetos de colonização formadores de braços temporários para a lavoura.

Pouco se tem notícia sobre o sucesso destes núcleos como viveiros de trabalhadores temporários sazonais para as fazendas de café. Na documentação pesquisada encontramos quase nenhuma referência aos núcleos como viveiros efetivos de trabalhadores sazonais. As referências encontradas se restringem a outras informações, tais como o sobre crescimento da produção e da variedade de itens cultivados, ou sobre a capacidade de os colonos quitarem a dívida de seus lotes.

Uma das poucas referências sobre a utilização dos residentes dos núcleos como trabalhadores temporários sazonais para as colheitas de café foi encontrada no Relatório da Secretaria da Agricultura de 1907, quando a pasta estava sob responsabilidade de Carlos Botelho, um dos mais ardorosos defensores da mecanização associada aos viveiros de braços temporários, tendo sido durante sua gestão à frente da Secretaria da Agricultura que importantes núcleos da segunda fase foram criados. $\mathrm{O}$ Relatório da Secretaria da Agricultura de 1907 informava que o governo havia fornecido turmas de colhedores para as fazendas, no total de 815 pessoas, vindas dos núcleos de Nova Odessa, Tibiriçá e Campos Salles (SECRETARIA dos Negócios da Agricultura, 1907). Foi também durante a gestão de Carlos Botelho que a Agência Oficial de Colonização e Trabalho foi criada regulamentando a possibilidade do subsídio estatal ao transporte da população dos núcleos para as colheitas.

Em 1911, Pierre Denis indagava: "A criação destas colônias tem fornecido aos fazendeiros de café, como era esperado, uma reserva de trabalho disponível no tempo da colheita? Aqui, novamente, nós teremos de esperar mais alguns anos antes de responder." (Denis, 1911, p. 231)

Seis anos depois, no Boletim do Departamento Estadual do Trabalho, encontramos resposta para sua indagação:

A experiencia não tem desmentido essa afirmação da doutrina. As fazendas situadas nas proximidades de núcleos coloniais ou em cujas redondezas se desenvolveu a pequena propriedade (...) não lutam, pelo menos por ocasião das colheitas, com dificulda- 
des tão grandes como as que assoberbam os proprietários de terras não favorecidos por aquelas duas condições. (EMIGRAÇÃO inter-regional para as colheitas, 1917, p. 278)

Logo em seguida, porém, o texto do Boletim informava que se a pequena propriedade (e nela incluídos os núcleos coloniais) não vinha produzindo, na medida desejada, os resultados em relação à mão de obra agrícola, isto era devido a uma destas duas causas:

$\mathrm{O} u$ os grandes fazendeiros não têm sabido aproveitar a vizinhança dos pequenos, obstinando-se na sua immoderada preferência pelos recemchegados; ou os pequenos proprietários têm encontrado para o exercício de sua actividade um campo de tal modo vantajoso, que não lhes sobra tempo ou disposição para acrescentar aos lucros do próprio sitio o salário que o chefe da família, os filhos e os agregados podem ganhar na fazenda mais próxima. (EMIGRAÇẨ inter-regional para as colheitas, 1917, p. 278)

Portanto, se, por um lado, a pequena propriedade era necessária para desonerar a fazenda cafeeira dos custos de manutenção do trabalhador nas épocas mortas do café, por outro lado, na prática, impedia a plena proletarização desse trabalhador, pois lhe permitia a obtenção de meios de subsistência, diminuindo a sua dependência em relação aos salários monetários e aumentando, assim, seu poder de barganha. Desta maneira, os núcleos coloniais, ao gerarem um custo de oportunidade ao trabalhador acabavam por diminuir a elasticidade da oferta de mão de obra, sendo incompatível, portanto, com economias altamente exigentes de mão de obra temporária sazonal.

Pelo nucleo nós capinaríamos os cafezaes com camaradas e na colheita recorreriamos ao nucleo, mas o habitante delle ou por não precisar ou por ter de trabalhar nas industrias provenientes da pequena propriedade, taes como a fabricação da farinha de mandioca, a extracção do mel de abelhas, a preparação do azeite de mamona, da manteiga e outras, impedil-o-ia 
de nos colher café. [...] E estas ainda não são as peiores hypotheses. O que succederia fatalmente era a imposição pelos proprietários do nucleo do preço da colheita. (Barros, 1907, p. 393)

Contrariamente ao que ponderavam os defensores da política de núcleos como viveiros de braços para as colheitas, o trabalhador que tinha acesso à terra sem estar ao mesmo tempo submetido a um contrato de trabalho com a grande fazenda (como era o caso no colonato), somente colocaria sua força de trabalho à disposição da grande propriedade quando as tarefas em seus lotes o permitissem e quando lhes fosse vantajoso. Caso contrário, com a subsistência garantida, o trabalhador não se submeteria ao trabalho nas grandes fazendas.

Outro fator que contribuiu para o pequeno resultado prático dos núcleos como viveiros de braços foi a dificuldade da migração temporária dos seus moradores para as fazendas situadas fora dos municípios onde eles estavam localizados, pois esta migração, mesmo que temporária, acabava por contrariar interesses políticos e econômicos locais. Como o transporte seria feito pelo poder público, por ordem do Secretário da Agricultura (cf. Art. 43 do Decreto que criou a Agência Oficial de Colonização e Trabalho), isto dificilmente pôde acontecer durante a Primeira República, período da história política brasileira em que a manutenção de interesses locais e regionais era tão importante:

Não se esqueceu o Poder Público de pôr à disposição dos colonos os meios de se transportarem às fazendas para as colheitas. Surge, porem, no fornecimento desses meios o factor do interesse regional, municipal, prejudicado pela saida, ainda que temporaria, de braços uteis para a lavoura. Esse modo de suprimento de mão de obra às grandes propriedades, fica, pois circumscripto aos respectivos municípios. (EMIGRAÇÃO inter-regional para as colheitas, 1917, p. 278).

Além do mais, os trabalhadores tinham de se manter muito próximos de seus lotes, visto que, apesar de as culturas da lavoura para exportação e dos núcleos serem passíveis de ser intercaladas, havia momentos em que algumas tarefas coincidiam no tempo, impossibilitando aos moradores 
dos núcleos se afastarem de seus lotes por longo período para colherem café em outro município:

Como a sementeira destes [cereais] se faz em Setembro, seria preciso que se começasse já em julho ou agosto, ou em se tratando de derribadas, já em junho, o mais tardar a preparar a terra. Mas este é exactamente o tempo da colheita de café, durante a qual o fazendeiro precisa de todos os braços disponíveis. [...] O colono pela sua parte, o mais tardar em abril, teria terminado suas colheitas e poderia assim ir colher café, levando até a mulher e os filhos. Em julho ou agosto ele poderia tornar a preparar terra para a sua sementeira em Setembro. (Kulmann, 1901, p. 29)

Desta maneira, apesar do uso rotineiro de trabalhadores extra fazenda (Moura, 1998 e 2007; Lamounier, 2000 e 2007; Tessari, 2010), o sistema de colonato ainda era o sistema que melhor se adequava às características do trabalho no café em São Paulo naquele momento. Ao prever a concessão de terras ao colono e seus familiares no interior da propriedade, conseguia ao mesmo tempo a manutenção da integridade territorial da fazenda e a submissão do colono, por meio do contrato, à obrigação de tratar e colher o café no momento que a fazenda exigisse. Além do mais, ao limitar os tipos e a quantidade de plantas que os colonos podiam cultivar, ${ }^{4}$ o contrato de colonato tentava evitar que o trabalho na lavoura de alimentos no interior da fazenda prejudicasse o trabalho no cafezal. (Sallum Jr, 1982, p. 166; Faleiros, 2007).

\section{Considerações Finais}

A análise das discussões em torno da mecanização do trato associada à criação dos núcleos coloniais nos permite entender o porquê de o trabalho temporário extra fazenda não ser preponderante naquele momento, apesar de já ser importante para estruturar a atividade

${ }^{4}$ Os contratos de colonato permitiam que os colonos cultivassem por conta própria apenas plantas que tivessem calendários de produção com altas e baixas demandas de trabalho intercalares ao café (geralmente: milho, feijão, arroz e batata) e restringiam a quantidade de cada planta de acordo com a proporção de pés de café sob responsabilidade do colono. 
produtiva. Em outras palavras, nos permite apreender em que medida era possível a inversão da relação trabalhador permanente (colono)/trabalhador temporário e em que medida era viável depender em demasia da utilização de trabalhadores desvinculados da grande propriedade, fossem eles camaradas, jornaleiros, empreiteiros, colhedores, sitiantes ou moradores dos núcleos.

As discussões mostram que naquele momento existia a consciência de que a produtividade e a lucratividade da lavoura dependiam da possibilidade de mecanização e da flexibilização do trabalho, porém, estas esbarravam em alguns fatores, o mais importante, a falta de oferta abundante de mão de obra que garantisse a oferta elástica de trabalhadores nos momentos de maior necessidade de trabalho.

No momento de crise da economia cafeeira do início do século XX, parte da elite cafeeira, em especial o grupo que defendia a modernização da agricultura por meio da ciência e de novas técnicas de produção, passou a questionar a política de mão de obra em São Paulo baseada no subsídio à imigração em massa e no sistema de colonato. Como solução para o problema que se colocava naquele momento - reduzir os custos com o trabalho frente à expansão da cafeicultura e à queda dos preços internacionais do café - passaram a defender a mecanização do trato associada à contratação de trabalhadores temporários na época da colheita.

Sabia-se que para mecanizar o cultivo do café e poder inverter a relação trabalhador permanente/trabalhador temporário, com este último sobrepujando o primeiro, era necessário ter mão de obra fácil, barata e abundante, disponível para ser arregimentada quando o trabalho na fazenda requisitasse. Nesse sentido, defendiam que os núcleos coloniais estrategicamente localizados poderiam promover o aumento da oferta de mão de obra temporária e ao mesmo tempo liberar as fazendas de ter de manter terras e trabalhadores ociosos durante os tempos mortos do café.

De acordo com aqueles que advogavam pelos núcleos coloniais, a alternativa de fixação do trabalhador ao lado das fazendas, em núcleos onde ele poderia se dedicar a culturas que tivessem pico de trabalho intercalar ao pico de trabalho na grande propriedade, permitiria a mecanização do trato do café, tarefa na qual estavam alocados os trabalhadores permanentes residentes (colonos), permitindo redução dos custos com mão de obra. 
No entanto, se alguns acreditavam ser possível a utilização de trabalhadores extra fazenda que intercalavam o trabalho na grande lavoura com o trabalho na lavoura própria de alimentos, a experiência lhes mostrava, também, que contar apenas com estes trabalhadores não era possível. Com acesso a terra, podendo escolher o que e quanto produzir e estando desobrigado de prestar serviço à grande lavoura, poderia não sobrar tempo ao trabalhador ou ele poderia não se interessar pelo trabalho na cultura para exportação, a não ser que a remuneração fosse compensadora.

Em uma atividade que tem discrepâncias entre o tempo de trabalho e o tempo de produção e discrepâncias entre os quantuns de trabalho nas diferentes etapas do processo produtivo, a lucratividade depende da flexibilização dos fatores de produção, especialmente o trabalho, em outras palavras, depende da possibilidade da pura compra de força de trabalho sem que o capitalista-fazendeiro tenha de ter responsabilidades outras na manutenção do trabalhador nos períodos de não trabalho. Além do mais, depende da facilidade de contratar, dispensar e recontratar mão de obra de acordo com as necessidades da produção.

Em uma sociedade em que a terra ainda era abundante, uma alternativa parecia ser distribuir terras, mas esta era justamente a alternativa mais contraditória, pois era este o fator primordial que impedia a plena proletarização do trabalhador. Enquanto os trabalhadores não fossem totalmente destituídos dos meios de subsistência, enquanto não dependessem totalmente dos salários para sobreviver, eles não constituiriam uma oferta típica de mão de obra necessária para a empresa capitalista. Não será à toa que a plena proletarização do trabalhador do campo em São Paulo ocorrerá somente anos mais à frente, quando a restrição do acesso a terra formará um exército abundante de mão de obra que permitirá a mecanização dos tratos culturais e transformará o trabalhador residente em trabalhador eventual (Mello, 1976; Brant, 1977; Silva, 1981). 


\section{Documentos Citados}

SOBRINHO, Julio Brandão (org.). Almanach Ilustrado do Lavrador Paulista para 1906 organizado por Julio Brandão Sobrinho, inspector do lo distrito agronomico. São Paulo: Duprat \& Comp., 1906.

BARROS, Dario Leite de. A cultura mechanica dos cafezaes. Revista Agricola, São Paulo, n. 143, p. 392-395, 15 jun. 1907.

CARMO, A. Gomes. Uma visita a fazenda do Senr. Carlos Botelho - cultura racional do café. Revista agricola, São Paulo, n. 46, p. 174-179, 15 mai. 1899.

CONDIÇÕES da lavoura no mez de setembro. In: Secretaria da Agricultura, Commercio e Obras Publicas do Estado de São Paulo. Boletim da Agricultura. Anno de 1901. São Paulo: Red. da Revista Agricola, serie 1, n. 9, p. 590-597, set. 1901.

DAVATZ, Thomas. Memórias de um colono no Brasil: 1850. Belo Horizonte: Ed. Itatiaia; São Paulo: Ed. da Universidade de São Paulo, 1980.

DENIS, Pierre. Brazil 1911. London: T. Fisher Unwin Ltd., 1911.

DUARTE, Carlos. Considerações sobre a cultura mechanica do cafeeiro. In: Secretaria da Agricultura, Commercio e Obras Publicas do Estado de São Paulo. Boletim da Agricultura. Anno de 1913. São Paulo: 14a serie, n. 5, p. 302-305, mai. 1913.

EMIGRAÇÃO inter-regional para as colheitas. In: Secretaria da Agricultura, Commercio e Obras publicas do Estado de São Paulo. Boletim do Departamento Estadual do Trabalho, ano 7, n. 23, p. 275-283, $2^{\circ}$ trim. 1917.

ESTATÍSTICA especial da lavoura de café nos municípios de Araçariguama, Atibaia, Bananal, Pilar, Sertãozinho e Redempção. In: Secretaria da Agricultura, Commercio e Obras Publicas do Estado de São Paulo. Boletim da Agricultura. Anno de 1900. São Paulo: Typ. do Diario Official, série 1, n. 6, jun 1900. (Suplemento).

FAUCHĖRE, A. Melhoramentos possiveis diante da situação economica da cultura cafeeira no Brasil. In: Secretaria da Agricultura, Commercio e Obras Publicas do Estado de São Paulo. Boletim da Agricultura. Anno de 1914. São Paulo: série 15, n. 4-5, p.400-404, abr--mai. 1914.

GAVIÃO PEIXOTO, B. A. O povoamento do solo. Cartas dos snrs Visconde de Ouro Preto e Conselheiro Gavião Peixoto sobre o assumpto. Revista Agricola, São Paulo, ano X, n. 114, 15, p. 31-37, jan. 1905.

GAZETA de Piracicaba. Piracicaba, SP, 14 ago. 1888, p. 3.

KULMANN, Alberto. Immigração. Revista Agricola, São Paulo, ano VI, n. 69, p. 1-40, 15 abr. 1901. (Suplemento)

MALTA, Francisco de Toledo. Homestead. Revista Agricola, São Paulo, ano X, n. 114, p. 1-4, abr. 1905.

MOTTA SOBRINHO, J. Cultura mechanica do cafeeiro. In: Secretaria da Agricultura, Commercio e Obras Publicas do Estado de São Paulo. Boletim da Agricultura. Anno de 1913. São Paulo: série 14, n. 11-12, p. 746-748, nov.-dez. 1913.

QUEIROZ, Luiz. Algumas palavras sobre a cultura do café. Revista Agricola, ano 1, n. 6, p. 93-94, 01 nov. 1895.

RAMOS, Augusto. O café no Brasil e no estrangeiro. Rio de Janeiro: Pap. Santa Helena, 1923.

SÃO PAULO. Decreto n. 1.355 de 10 de abril de 1906, que cria a Agencia Official de Colonisação e Trabalho. In: Secretaria da Agricultura, Commercio e Obras Publicas do Estado de São Paulo. Boletim da Agricultura. Anno de 1906. São Paulo: Red. da Revista Agricola, série 7, n. 4, p. 145-154, abr. 1906.

SECRETARIA dos Negocios da Agricultura, Commercio e Obras Publicas do Estado de São Paulo. Relatorio de 1903 pelo Dr. Luiz de T. Piza e Almeida, Secretario da Agricultura. São Paulo: Typographia do Diario Official, 1904.

SECRETARIA dos Negocios da Agricultura, Commercio e Obras Publicas do Estado de São Paulo. Relatorio apresentado ao Dr. Jorge Tibiriçá, presidente do Estado de São Paulo pelo Dr. Carlos 
Botelho, Secretario da Agricultura. Anno 1904. São Paulo: Typographia Brazil de Carlos Gerke, 1905.

SECRETARIA dos Negocios da Agricultura, Commercio e Obras Publicas do Estado de São Paulo. Relatorio apresentado ao Dr. Jorge Tibiriçá, presidente do Estado de São Paulo pelo Dr. Carlos Botelho, Secretario da Agricultura. Anno 1906. São Paulo: Typographia Brazil de Carlos Gerke, 1907.

SECRETARIA dos Negocios da Agricultura, Commercio e Obras Publicas do Estado de São Paulo. Relatorio apresentado ao Dr. Jorge Tibiriçá, presidente do Estado de São Paulo pelo Dr. Carlos Botelho, Secretario da Agricultura. Anno 1907. São Paulo: Typ. Brazil de Rothschild \& Co, 1908.

SECRETARIA dos Negocios da Agricultura, Commercio e Obras Publicas do Estado de São Paulo. Relatorio apresentado ao Dr. M. J. Albuquerque Lins, presidente do Estado pelo Dr. Antonio Candido Rodrigues, Secretario da Agricultura. Anno de 1908. São Paulo: Typ. Brasil de Rothschild \& Cia, 1909.

SECRETARIA dos Negocios da Agricultura, Commercio e Obras Publicas do Estado de São Paulo. Relatorio apresentado ao Dr. Carlos Augusto Pereira Guimarães, vice-presidente do Estado em exercício pelo Dr. Paulo de Moraes Barros, secretario de Estado. Annos de 1912-1913. São Paulo: Typ. Brasil de Rothschild \& Cia, 1914.

SOUZA, Everardo. Evolução agricola de São Paulo. Revista Agricola. São Paulo, ano 10, n. 118, p. 206-214, 15 mai. 1905.

\section{Referências}

BASSANEZI, Maria Silvia C. Beozzo. Fazenda de Santa Gertrudes. Uma abordagem quantitativa das relações de trabalho em uma propriedade rural paulista. 1895-1930. Rio Claro, SP: 1973. Tese (Doutorado) - Faculdade de Filosofia, Ciências e Letras, Unesp.

BeIGUELMAN, Paula. A Formação do povo no complexo cafeeiro. Aspectos políticos. São Paulo: Edusp, 1971.

BRANT, Vinícius Caldeira. Do colono ao bóia-fria: transformações na agricultura e constituição do mercado de trabalho na Alta Sorocabana de Assis. Estudos Cebrap, São Paulo, n. 19, p. 37-92, 1977.

FALEIROS, Rogério Naques. Fronteiras do café: fazendeiros e "colonos" no interior paulista (19171937). Campinas, SP: 2007. Tese (Doutorado) - Instituto de Economia, Unicamp.

FERRARO, Mário Roberto. Ciências, Meio Ambiente e Cultura na Belle Époque Paulista: o "day after" da lavoura cafeeira. Campinas, SP [s.n.], 2012.

GADELHA, Regina Maria D’Aquino Fonseca. Os núcleos coloniais e o processo de acumulação cafeeira (1850-1920): contribuição ao estudo da colonização em São Paulo. São Paulo: 1982. Tese (Doutorado) - Departamento de História, Faculdade de Filosofia, Letras e Ciências Humanas, USP.

GORENDER, Jacob. O escravismo colonial. São Paulo: Ática, 1985.

HOLLOWAY, Thomas H. Imigrantes para o Café: café e sociedade em São Paulo, 1886-1934. Rio de Janeiro: Paz e Terra, 1984.

LAMOUNIER, Maria Lúcia. Agricultura e mercado de trabalho. Trabalhadores brasileiros livres nas fazendas de café e na construção das ferrovias em São Paulo, 1850-1890. Estudos Econômicos, São Paulo, v. 37, n.2, p. 353-372, abr.-jun. 2007.

. Ferrovias, agricultura de exportação e mão de obra no Brasil no século XIX. História Econômica \& História de Empresas, São Paulo, vol. 3, n. 1, p. 43-76, jan.-jun. 2000.

MELLO, Maria Conceição D’Incão. O “Bóia-Fria”: acumulação e miséria. Petrópolis, RJ: Vozes, 1976.

Estud. Econ., São Paulo, vol. 44, n.2, p. 409-434, abr.-jun. 2014 
MOURA, Denise A Soares de. Saindo das sombras: homens livres no declínio do escravismo. Campinas, SP: Área de Publicações CMU/Unicamp, 1998.

. Cafeicultores e lavradores de roças de alimentos na transição do trabalho escravo ao livre (Campinas, 1850-1888). América Latina en la Historia Económica, v. 27, p. 79-110, jan.-jun. 2007.

PETRONE, Maria Tereza Schorer. Imigração. In: HOLANDA, Sergio Buarque de. História geral da civilização brasileira: O Brasil Republicano. São Paulo: Difel, 1985, tomo III, vol. 2, p. 93-133.

REZENDE, Gervásio Castro de. Políticas trabalhista, fundiária e de crédito agrícola no Brasil: uma avaliação crítica. Revista de Economia e Sociologia Rural, Rio de Janeiro, vol. 44, n. 1, p. 47-78, jan.-mar. 2006.

SALLUM Jr., Brasilio. Capitalismo e cafeicultura: oeste paulista, 1888-1930. São Paulo: Duas Cidades, 1982.

SILVA, José Graziano da. Progresso Técnico e Relações de Trabalho na Agricultura. São Paulo: Editora Hucitec, 1981. (Economia e Planejamento)

STOLCKE, Verena; HALL, Michael. A introdução do trabalho livre nas fazendas de café de São Paulo. Revista Brasileira de História. São Paulo, 3, n. 6, p. 80-120, set. 1983.

STOLCKE, Verena. Cafeicultura. Homens, mulheres e capital (1850-1980). São Paulo: Brasiliense, 1986.

TESSARI, Cláudia Alessandra. Braços para colheita: sazonalidade e permanência do trabalho temporário na agricultura paulista (1890-1915). Campinas, SP: [s.n.], 2010. Tese (Doutorado) - Instituto de Economia, Unicamp.

VANGELISTA, Chiara. Os braços da lavoura. Imigrantes e "caipiras" na formação do mercado de trabalho paulista (1850-1930). São Paulo: Hucitec/Instituto Italiano di cultura/Instituto Cultural Ítalo-Brasileiro, 1991. 